\title{
THE RELATIONSHIP BETWEEN BETTING AND LOTTERY PLAY
}

\author{
DAVID FORREST, O. DAVID GULLEY, and ROBERT SIMMONS*
}

\begin{abstract}
We apply a novel daily time series data set of daily turnover from one of Britain's leading bookmakers to analyze potential substitution between lottery play and bookmaker betting. We find some evidence that bettors do substitute away from horse race, soccer and numbers betting when the effective price of lottery tickets is unusually low, that is, when there is a rollover or other special draw. This substitution has a highly specific pattern of timing that varies by sector. Our results further suggest that bettors rationally engage in forward-looking substitution within their betting portfolios. (JEL D12, L83)
\end{abstract}

\section{INTRODUCTION}

The range of modes of gambling permitted to operate legally has expanded markedly in many jurisdictions in North America and Europe and many states are debating further liberalization. One focus of research relevant to analysis of likely consequences of such policy has been the relationship between different gambling industries. This article contributes to the limited evidence available by examining linkages between two sectors, betting services market, and the state lottery.

The prior literature, most of it based on American data, focuses on the displacement effects on pari mutuel wagering from the introduction or presence of a lottery. For example, Simmons and Sharp (1987) and Thalheimer and Ali (1995) reported impacts on pari mutuel turnover of between $-10 \%$ and $-36 \%{ }^{1}$ These

\footnotetext{
*We wish to thank participants at the 80th Western Economic Association Annual Conference, San Francisco, and two anonymous referees for constructive suggestions. We are grateful to the anonymous bookmaking company, which provided the bulk of the data for our analysis. D.F. acknowledges support from a Leverhulme Fellowship. O.D.G. was supported by the Gibbons Research Professorship.

Forrest: Professor, Centre for the Study of Gambling, University of Salford, Salford M5 4WT, UK. Phone 0044-161-295-3674, Fax 0044-161-295-2130, E-mail d.k.forrest@salford.ac.uk

Gulley: Professor, Department of Economics, Bentley College, Waltham, MA 02452. Phone 781-891-2355;

Fax 781-891-2896; E-mail dgulley@bentley.edu Simmons: Senior Lecturer, Department of Economics,

The Management School, Lancaster University, Lancaster LA1 4YX, UK. Phone 0044-1524-594234, Fax 0044-1524-594244, E-mail r.simmons@lancaster.ac.uk

1. See Kaplan (1992) and Thalheimer (1992) for further evidence of displacement effects between horse racing and lotteries in the United States.
}

findings suggest that notwithstanding that horse betting and lotteries offer very different products in terms of the structure of prizes, the degree to which skill is relevant and the social context in which consumption takes place, a significant number of bettors are nevertheless willing to shift wagers between the sectors when one that was previously unavailable is introduced into their jurisdiction.

Some writers refer to this displacement as substitution, but it is not substitution according to standard economic usage where the definition of substitutes is that cross-price elasticity of demand between goods is positive. A new product, introduced with a specific price, may cannibalize the market for an existing product, but that does not tell us how different the degree of cannibalization may have been with a different price or how sensitive consumers will be to any variation in future relative prices as between the sectors.

A recent comprehensive report on gambling for the European Union (Swiss Institute of Comparative Law 2006, pp. 1428-1441) includes detailed tabulation of empirical findings on gambling markets in peer-reviewed literature. On the basis of several studies of own-price elasticity, it concludes that betting demand is typically highly sensitive to track or bookmaker takeout. This has policy implications, for example, it suggests that monopoly provision of betting services in a jurisdiction

\section{ABBREVIATIONS}

ADF: Augmented Dickey-Fuller UKNL: UK National Lottery 
will suppress a large volume of betting, and it suggests that reductions in tax rates may raise state revenue.

The same report, however, reveals a paucity of studies of cross-price effects between modes of gambling. Thus, while it appears that total betting expenditure is very sensitive to value for money, and a fairly substantial literature ${ }^{2}$ shows that lotto demand also displays at least unit elasticity, it is not known how readily gambling dollars or euros will be shifted between betting and lotteries if relative prices change. This would be desirable to know as an input to analysis of gambling policy. For example, secular decline in lottery sales has lead to pressure on take-out rates, which have fallen in parts of the United States (while the United Kingdom debates the repeal of a $12 \%$ Treasury tax on tickets to allow bigger lotto prizes). What costs and benefits are implied by offering lottery players better payouts? Will it damage the horse racing and breeding industries by drawing money away from wagering? Will it shift a significant volume of gambling from a "hard" form of gaming (betting) to a "soft" form (lotteries)? Does prohibiting access to low-cost wagering supplied via the Internet (as in the United States and France) protect the state lottery sector as well as domestic betting suppliers? These are the sorts of questions that require knowledge of whether and to what extent variation in value for money offered by lotteries induces reallocation of expenditure away from betting. Access to a unique data set on betting with a prominent UK bookmaker permits us to offer an assessment.

We study the relationship between betting volumes with that bookmaker and drawby-draw variation in value offered to purchasers of lotto, an online numbers game that accounts for the majority of the turnover of the UK National Lottery (UKNL). The game is similar in format to that offered by many American states. Draws take place twice weekly, on Wednesday and Saturday evenings. A player pays 1 pound to select six numbers in the range $1-49$. If his selection matches the six winning numbers in the televised draw, he wins a share of the grand prize. If no player wins this jackpot, the money is "rolled over" to the next draw. The size of jackpot on offer

2. For British examples, see Farrell, Morgenroth, and Walker (1999) and Forrest, Simmons, and Chesters (2002). in lotto therefore varies not only with the number of tickets sold but also with whether (and how much) prize money has been rolled over from previous draws. In the British version of the game, further variation in prize levels between draws occurs because the operator is permitted to reserve some revenue to fund occasional promotional "Superdraws" where extra money is added to the jackpot. As with rollovers, lotto on these occasions offers potential players better value: the expected value of holding a ticket can be as much as twice as high for some draws (those benefiting from a double rollover where the jackpot has been unwon two draws running) as for others. We make use of the variation in the data generated by the presence of rollovers and Superdraws to test whether some of the increase in sales observed on these occasions is at the expense of the betting sector. Draw-by-draw sales and prize data for lotto were retrieved from an archive held at www.merseyworld.com.

We were supplied with over 5 yr of daily data on turnover in four forms of gambling offered by a major national but, for commercial reasons, anonymous British bookmaker. ${ }^{3}$ For each product type (such as horse race betting), we built a detailed model to account for variation in turnover and included terms to allow us to estimate the response of sales on the day of, and in the days running up to, lotto rollovers and Superdraws. ${ }^{4}$ The findings are striking in that some, but not all, forms of betting prove to be sensitive to the amount of prize money available in the lotto game. However, the existence of significant substitution effects depends critically on the timing of betting in relation to an anticipated rollover. These intertemporal effects can only be revealed by the type of high-frequency data that we have available here. Lotto and certain forms of wagering are therefore demonstrated to be substitutes, dependent on time of betting, and this has policy implications discussed below. These substitution effects are particularly interesting

3. In further recognition of the commercial sensitivity of the information provided, we transformed the turnover data into index number format prior to empirical analysis. A fifth sector, sports betting (excluding soccer) was not included in our model because its volume is small and very heterogeneous in terms of the sort of events covered. We also exclude from the analysis slot machine play, which, in this period, was too small in volume to be of interest.

4. We tested also for any impact in the days following a rollover or Superdraw but found nothing significant and do not report the results. 
as the United Kingdom moves forward toward further deregulation of the gambling sector following passage of the Gambling Act (2005), which became law in late 2007 and which will open up greater opportunities for access to established gambling products and entry of new betting opportunities.

While studies of cross elasticities have been rare in gambling, two previous articles have in fact, like us, attempted to exploit, in analysis of betting, variations in effective lotto price associated with the phenomenon of rollovers. Purfield and Waldron (1999) found that rollovers of the Irish lotto raised both lotto sales and the volume of side betting (with a major Irish bookmaker) on which numbers were drawn. The complementary relationship is interesting in that it may arise because lotto buyers not only respond to value in the draw itself by purchasing more tickets but also take advantage of the greater emphasis on small prize, high-probability wagers in the side betting market to create a lottery portfolio that accords with their preferences over variance and skewness in returns. The results pertain, however, to the special case of betting on the lotto game itself and do not give any clue as to how mainstream betting is affected by an effective price reduction available at the lottery booth.

In the second study to use rollover-induced variation in the effective price of lotto to illuminate the relationships between gambling sectors, Paton, Siegel, and Vaughan Williams (2004) employed monthly data on UK betting tax revenue. They modeled the response of UK betting volume, as recorded by Customs and Excise, to lotto "price" (i.e., expected loss from one play). ${ }^{5}$ However, because only monthly data were available, the price variable had to be constructed from averaging across up to nine lotto draws, which raises problems over the weighting that should be given to different draws whose sales will vary substantially according to whether or not there is a rollover. Further, the reliance on monthly data aggregates away much of what may be interesting in terms of the impact of lottery events on betting patterns. The present study

5. Taking their analysis beyond 2001 enabled Paton, Siegel, and Vaughan Williams to evaluate the effects of major changes in betting tax introduced in October 2001. However, their data, based on bookmaker tax returns, include revenue from fixed odds betting terminals and casino style gaming machines, which were introduced into bookmaker shops, exploiting a legal loophole, after 2001. This is likely to have distorted their results. has the advantage of daily turnover data that is also disaggregated according to different forms of wagering. The nature of substitution from the betting sector to lotto can therefore be revealed in greater and more reliable detail.

\section{LOTTERY AND BETTING IN THE UNITED KINGDOM}

As background, we provide first information on participation in betting and lottery play. Each form of gambling is very widely available through dense (but completely separate) retail networks. At the last official count in 2000, there were 8,732 bookmaker shops (quoted in Mintel [2003]) and this figure has remained almost unchanged since then, according to the Association of British Bookmakers (www.abb.uk.com). These bookmaker shops are not permitted to sell tickets for, or accept side bets on, National Lottery products. Lottery tickets are sold at post offices, many convenience stores, and nearly all supermarkets and petrol stations. Except in the most rural areas, UK residents therefore enjoy very ready access to both types of gambling opportunity. Locations, such as shopping areas in the suburbs, where there are one or more bookmakers, will almost invariably host a National Lottery outlet as well. According to Department for Culture, Media, and Sport (2001), betting turnover in 1998, the middle year of our data period, was $£ 8.4 \mathrm{bn}$ and sales of National Lottery products amounted to $£ 5.4 \mathrm{bn}$.

For information on the extent of overlap of customers between the two markets, we examined data from the Family Expenditure Survey. The 2001 Edition, relating to the final year of our bookmaker data set, included categories of expenditure for lotto games (which excluded purchases of scratch cards offered by the

\section{TABLE 1}

Participation in Betting and Lotto Games by UK Households

\begin{tabular}{lccc}
\hline & Betting (\%) & Nonbetting (\%) & All \\
\hline Lotto & $808(12.17)$ & $3,046(45.89)$ & $3,854(58.07)$ \\
Nonlotto & $255(3.84)$ & $2,528(38.09)$ & $2,783(41.93)$ \\
All & $1,075(16.20)$ & $5,562(83.80)$ & 6,637 \\
\hline
\end{tabular}

Notes: Data are number of households included in the Family Expenditure Survey (2001) according to whether they recorded expenditure in the relevant category during a 2-wk membership of the panel. 
National Lottery) and for betting at bookmakers. Summaries of spending diaries were available for each of 6,637 households, which comprised a rolling sample, with each household taking part for $2 \mathrm{wk}$. Table 1 shows the numbers and proportions of households classified according to participation/nonparticipation in the two modes of gambling. Sixty-two percent of all households took part in one or both activities during their $2 \mathrm{wk}$ in the Survey, according to their spending records $(100 \%-$ $38.09 \%$ from the "abstainers" cell, marked nonlotto nonbetting in Table 1). Of particular note in the table is that $75 \%$ of households who bet at bookmakers also purchased the lottery (808 divided by 1,075 from the "Betting" column of Table 1). ${ }^{6}$ If households reallocate their gambling portfolios according to variations in relative price, this makes bookmaking potentially vulnerable if takeout falls in the lotto game, depending of course on the degree of sensitivity to value for money. It is this sensitivity that we seek to evaluate.

\section{BOOKMAKER DATA}

A large bookmaker whose retail network gives national coverage provided daily data for the volume of business transacted at shop outlets ${ }^{7}$ during the period from January 1, 1996, to June 5,2001 . For purposes of the analysis below, we converted all data to "real" pounds according to the all items Retail Price Index of June 2001.

A complication was that the period was marked by a gradual move toward more regular Sunday opening of bookmaker shops. The data therefore sometimes recorded Sunday business, but sometimes there was no business to record. Our model of turnover was to include both lagged dependent variables and dummy variables for days of the week. Controlling for the latter, our analysis revealed a degree of habit formation such that the amount staked on any $1 \mathrm{~d}$ reflected, at least for some products, the amount bet the day before and on the same day the previous week. To establish a consistent lag structure, it was necessary to treat each week as having the same number of days. Accordingly, we aggre-

6. Among these households, there was a very strongly significant positive correlation between the amounts spent on each mode (correlation coefficient .14).

7. Telephone and Internet wagering and on-track betting were therefore excluded. In the period to which our data relate, and even now, the bulk of betting took place through personal visits to bookmaker shops. gated our Saturday and Sunday data as if the weekend were a composite "day." To account for the boost to turnover when there was in fact Sunday opening, we then included in our models a dummy variable set equal to one if the day actually covered two calendar days when the shops were open for business.

Our analysis relates to four types of gambling offered at the shops. The total amounts wagered were provided for betting on horse racing, dog racing, soccer matches, and numbers games. ${ }^{8}$ Each of these sectors offers virtually daily betting opportunities and can be thought of as potential substitutes to lottery play. The pattern of average turnover by activity is shown for each day of the week in Figure 1.

The bookmaker also provided a wealth of data relevant to modeling turnover for the four sectors, for example, measures of the quantity and quality of each day's racing program, the dates of major sporting events, and the dates on which the range of numbers games on sale were altered.

\section{MODEL}

We began our model specification by testing for unit roots in the data. Augmented DickeyFuller (ADF) tests clearly rejected the null hypothesis of an $I(1)$ nonstationary process in favor of stationarity for two of our sectors. The test statistics for our betting sectors, based on 12 lags without trend, were $-3.74,-4.21$, -6.22 , and -2.62 for horses, dogs, soccer, and numbers, respectively, to be compared with a critical value of -2.86 at $5 \%$ significance and -2.57 at $10 \%$. Although the unit root test for numbers only rejects the null of nonstationarity at $10 \%$, we are inclined to accept stationarity. We were drawn to this conclusion by the low power of the test and inspection of the autocorrelation function. Moreover, there are several structural breaks in numbers turnover, reflecting periodic retirement, and initiation of different games. These make interpretation of the ADF test statistic problematic for this

8. Numbers games are based on daily draws commissioned by a consortium of bookmakers or on the drawings of foreign lotteries. They are similar in format to lotto, but payouts are based on matching less than a complete set of numbers drawn with no parallel to lotto's large grand prize for players matching all balls. On the other hand, payouts corresponding to small lotto prizes are much more generous than in the official game as bookmaking is very lightly taxed compared with the UKNL. Entry into numbers games is made at the shop counter in the same way as for other bets (i.e., they are not sold from machines). 
FIGURE 1

Average Daily Turnover by Sector

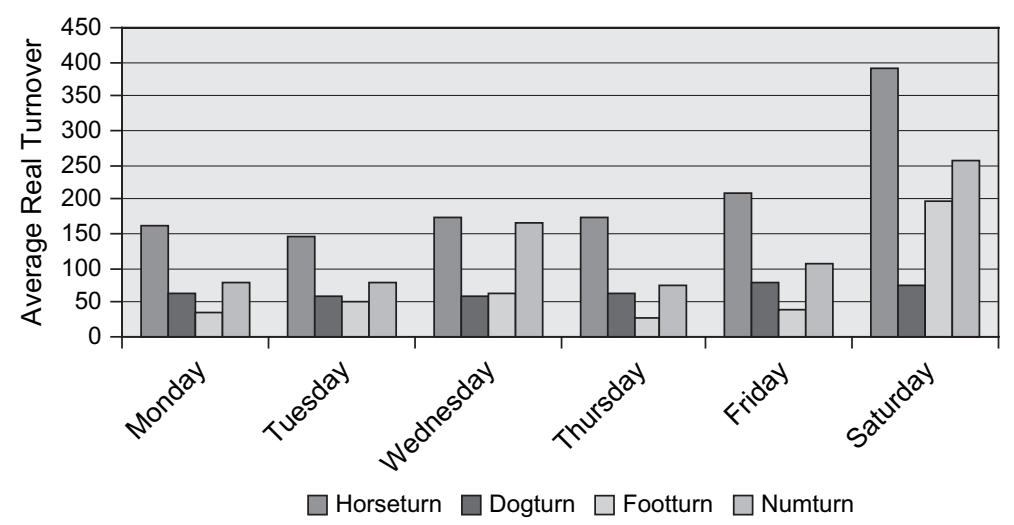

Note: Left-hand scale relates to data transformed as described in the text.

category. Overall, we concluded that differencing the data and search for cointegrating relationships were not required.

Estimation for each of the bookmaking sectors by ordinary least squares was deemed inappropriate because clients in the betting shop will decide simultaneously on which mix of events to place their wagers. This would yield nonzero correlation between the error terms across the four equations corresponding to the four betting sectors. We therefore employed Zellner's seemingly unrelated regression model, which provides joint estimates of our four sectoral regression models, allowing for potential correlation of the contemporaneous error terms. Turnover in each of the sectors is modeled as follows: ${ }^{9}$

$$
\begin{aligned}
& \text { TURNOVER }_{i t} \\
& =f \text { (constant, } \boldsymbol{T U} \boldsymbol{R} \boldsymbol{N} \boldsymbol{O} \boldsymbol{V E} \boldsymbol{R}_{i, \text { lagged, }} \\
& \text { WEDNESDAY BONUS, } \\
& \text { WEDNESDAY BONUS }{ }_{\text {Tuesday, }} \\
& \text { WEDNESDAY BONUS } \text { Monday, }_{\text {, }} \\
& \text { SATURDAY BONUS, } \\
& \text { SATURDAY BONUS } \text { Friday }_{\text {, }} \\
& \text { SATURDAY BONUS } \text { Thursday, }_{\text {, }} \\
& \text { CONTROLS }{ }_{i t} \text { ) }
\end{aligned}
$$

9. We do not include lotto itself in our demand system because decisions on lotto purchase are taken by a much wider constituency of players than the minority who engage in betting. We do not have data on level of lotto play by users of this bookmaker chain.
TURNOVER $_{i t}$ refers to sales in sector $i$ on

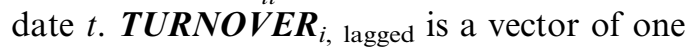
or more lagged values of turnover in sector $i$. Lagged values of turnover may be relevant because of the tendency for habit formation present in the consumption of many goods. We focus here on two lags: previous day and same day last week. If previous day's turnover is higher then today's turnover may be higher as bettors reinvest their winnings. Also, in some sectors, bettors appear to display habit persistence week to week; for example, increased numbers turnover on a given Saturday is followed by greater numbers turnover on the following Saturday.

The National Lottery variables, WEDNESDAY BONUS and SATURDAY BONUS, reflect that the behavior of potential players may be influenced by any bonus money added to the jackpot both on the day of the draw (when tickets may be purchased up to 7.30 p.m.) and on the two preceding days. For example, it is known on Wednesday evening whether anyone has won the lotto jackpot for that day's draw. If there is a rollover, the amount of prize money to be carried forward to Saturday is announced immediately and will inform decisions on how many tickets to buy during Thursday, Friday, and Saturday. Similarly, if lotto and betting are substitutes, there may be an impact on bookmaker turnover on Thursday, Friday, or Saturday. Suppose the amount $£ x$ is rolled over to Saturday. For the observation corresponding to the 
Thursday, SATURDAY BONUS $_{\text {Thursday }}$ is then equal to $x$ and the other lottery variables have the value 0 . For observations corresponding to that Friday and that Saturday, it is SATURDAY BONUS Friday $_{\text {and SATUR- }}$ DAY BONUS, respectively, that are set equal to $x$. Coefficient estimates on SATURDAY BONUS $_{\text {Thursday }}$, SATURDAY BONUS ${ }_{\text {Friday }}$, and SATURDAY BONUS therefore measure the impacts on bookmaker turnover (per pound of money added to the Saturday jackpot) on the Thursday, Friday, and Saturday of a week in which the Saturday lotto draw has become especially attractive.

BONUS is the amount of money in the form of rollover and Superdraw funds that augments the jackpot prize. The restriction that impacts of rollover and Superdraw on betting turnover are treated as identical is imposed here because of low frequencies in the rollover and Superdraw categories and is plausible in that rational bettors would treat an addition to the jackpot prize as equivalent, regardless of source. ${ }^{10}$ Adding rollover and Superdraw together gives greater precision in our estimates not only because of the greater number of "bonus" events but also because aggregation gives greater variation in the value of the BONUS variables. The separation of BONUS effects by Wednesday and Saturday draws reflects the findings of Forrest, Simmons, and Chesters (2002) that UKNL lotto turnover itself responded differently to movements in effective price and jackpot prize according to whether it was a Wednesday or Saturday draw.

We use BONUS in preference to a measure of price (the 1 pound entry fee minus the expected value of holding a ticket) because the amount of money rolled over from the previous draw is exogenous, whereas price would potentially be endogenous since, given the nature of the lotto game, expected value itself increases with the number of tickets sold (and therefore with the number of pounds attracted from betting). Note, however, that the relationship between BONUS and price is always such that if BONUS is increased, price falls. An illustration of this is shown in Figure 2 where we display the expected value of holding a lotto ticket for each level of sales, given two possible BONUS amounts, 0 and $£ 5 \mathrm{~m}$. Note

10. A caveat is that rollovers and Superdraws may be accompanied by different levels of advertising expenditure and publicity.

\section{FIGURE 2}

Relationship Between Expected Value of a Lotto Ticket and Number of Tickets sold

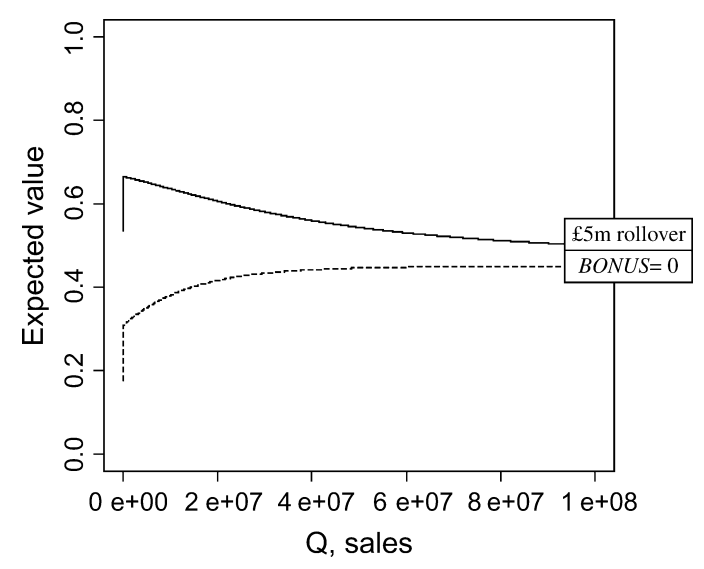

that increased sales in response to a rollover may dilute but cannot eliminate the expected value/price advantage of the rollover compared with the nonrollover draw. It follows that if we find a negative relationship between betting turnover and BONUS, there will also be a positive relationship with lotto price and the two products will therefore be substitutes in the standard economic sense.

CONTROLS is a vector of control variables specific to the particular bookmaker product. For each betting sector $i$, a large number of control variables were included to account for the substantial day-to-day variation in the volume of betting transactions. These controls include the number of betting shops open on a given day, a weekly time trend, dummy variables for month and day of week, variables to represent quality and quantity of events in a particular betting sector, and variables that capture possible substitution or complementarities in other betting sectors. A full list of all control variables is provided in the Appendix. In our model specification, we adopted a general-to-specific modeling procedure where controls were deleted if they were not significant at the $10 \%$ level. All models contain at least one lagged dependent variable.

\section{RESULTS}

\section{A. Horse Race Betting}

Table 2 reports Seemingly Unrelated Regression estimates for daily turnover in 
TABLE 2

SUR Betting Turnover Estimates

\begin{tabular}{|c|c|c|c|c|}
\hline Variable & (1) Horse Race & (2) Dog Race & (3) Soccer & (4) Numbers \\
\hline Turnover $(t-1)$ & $0.074(8.39)^{* * *}$ & $0.081(5.65)^{* * *}$ & $0.092(6.21)^{* * *}$ & $0.107(6.10)^{* * *}$ \\
\hline Turnover $(t-6)$ & & $0.170(11.37)^{* * *}$ & $0.123(8.69)^{* * *}$ & $0.463(34.58)^{* * *}$ \\
\hline Shops & $0.058(13.04)^{* * *}$ & $0.015(10.38)^{* * *}$ & & $0.010(3.36)^{* * *}$ \\
\hline Week & $-0.120(15.77)^{* * *}$ & $-0.054(19.66)^{* * *}$ & & \\
\hline \multicolumn{5}{|l|}{ Lottery variables } \\
\hline Wednesday Bonus & $-0.386(0.82)$ & $0.063(0.40)$ & $-1.426(2.35)^{* *}$ & $-0.344(1.00)$ \\
\hline Wednesday Bonus Tuesday & $-0.050(0.11)$ & $-0.089(0.56)$ & $-0.006(0.01)$ & $-0.092(0.27)$ \\
\hline Wednesday Bonus Monday & $-1.116(2.35)^{* *}$ & $-0.167(1.04)$ & $0.432(0.72)$ & $-0.219(0.63)$ \\
\hline Saturday Bonus & $-0.331(1.01)$ & $0.144(1.30)$ & $-0.263(0.63)$ & $-0.953(4.01)^{* * *}$ \\
\hline Saturday Bonus Friday & $-0.205(0.63)$ & $-0.008(0.07)$ & $0.280(0.68)$ & $-0.077(0.33)$ \\
\hline Saturday Bonus Thursday & $-0.601(1.86)^{*}$ & $-0.083(0.76)$ & $0.052(0.13)$ & $-0.350(1.49)$ \\
\hline \multicolumn{5}{|l|}{ Horse race variables } \\
\hline Prize money & $0.103(20.65)^{* * *}$ & & & \\
\hline Total runners & $0.430(24.39)^{* * *}$ & $0.038(6.47)^{* * *}$ & & $0.029(2.32)^{* *}$ \\
\hline Total runners squared & $-0.00028(13.03)^{* * *}$ & $-0.00003(4.54)^{* * *}$ & & $-0.00007(4.35)^{* * *}$ \\
\hline Grand National & $512.2(56.85)^{* * *}$ & $-24.80(8.18)^{* * *}$ & $-53.25(4.45)^{* * *}$ & $-23.80(3.72)^{* * *}$ \\
\hline Big meeting & $38.70(12.17)^{* * *}$ & & $-10.42(2.80)^{* * *}$ & \\
\hline TV races & $3.374(10.33)^{* * *}$ & $-1.522(15.58)^{* * *}$ & & \\
\hline Bookmaker TV races & $0.732(2.66)^{* *}$ & $-1.032(11.26)^{* * *}$ & & $-0.897(4.58)^{* * *}$ \\
\hline Bookmaker TV races squared & $-0.016(2.09)^{* *}$ & $0.0061(2.35)^{* *}$ & & $0.030(5.29)^{* * *}$ \\
\hline Irish flat races & $13.84(4.21)^{* * *}$ & & & \\
\hline Irish jump races & $1.077(4.52)^{* * *}$ & $-0.411(5.23)^{* * *}$ & & \\
\hline Foreign races & $11.99(7.53)^{* * *}$ & $-1.208(2.26)^{* *}$ & & \\
\hline 1st favourite won & $0.186(3.80)^{* * *}$ & & & \\
\hline 2nd favourite won & $0.274(4.63)^{* * *}$ & & & \\
\hline 1st favourite won $(t-1)$ & $0.262(5.43)^{* * *}$ & & & \\
\hline 2nd favourite won $(t-1)$ & $0.185(3.15)^{* * *}$ & & & \\
\hline \multicolumn{5}{|l|}{ Dog race variables } \\
\hline Morning dog races & $-0.622(5.05)^{* * *}$ & $0.544(12.42)^{* * *}$ & & \\
\hline Afternoon dog races & $-0.752(6.68)^{* * *}$ & $0.887(22.58)^{* * *}$ & $0.524(4.70)^{* * *}$ & $0.404(5.18)^{* * *}$ \\
\hline Winning dog favourite & & $0.074(3.46)^{* * *}$ & & \\
\hline \multicolumn{5}{|l|}{ Soccer variables } \\
\hline Bank holiday soccer & $49.89(8.27)^{* * *}$ & & $24.18(3.29)^{* * *}$ & $-25.06(5.68)^{* * *}$ \\
\hline Bank holiday Scottish soccer & & $7.630(2.22)^{* *}$ & $30.31(2.24)^{* *}$ & \\
\hline England in World Cup Final & & & $168.22(19.50)^{* * *}$ & \\
\hline World Cup Final & & & $176.35(13.79)^{* * *}$ & \\
\hline England v Scotland (Euro 1996) & & & $81.73(3.03)^{* * *}$ & \\
\hline $\begin{array}{l}\text { England v Scotland } \\
\text { (World Cup qualifier) }\end{array}$ & & & $100.87(5.36)^{* * *}$ & \\
\hline Scotland in Euro 1996 & $-32.60(2.28)^{* *}$ & & & \\
\hline FA Cup Final & $-25.09(2.93)^{* * *}$ & & $156.06(13.69)^{* * *}$ & \\
\hline FA Cup round & & & $79.03(12.81)^{* * *}$ & \\
\hline English club in European final & & & $108.68(8.07)^{* * *}$ & \\
\hline European club match & & & $30.44(12.42)^{* * *}$ & \\
\hline Premier games & & & $6.856(14.64)^{* * *}$ & \\
\hline Football League games & & & $4.664(12.07)^{* * *}$ & \\
\hline \multicolumn{5}{|l|}{ Other events } \\
\hline Wimbledon mens final & & $-10.79(3.36)^{* * *}$ & $-66.06(5.25)^{* * *}$ & $-21.52(3.08)^{* * *}$ \\
\hline Rugby League Cup Final & & $4.865(1.73)^{*}$ & & \\
\hline U.S. open golf & & $-2.166(2.18)^{* *}$ & & \\
\hline British open golf & & & $-20.08(3.16)^{* * *}$ & \\
\hline$R^{2}$ & 0.961 & 0.798 & 0.885 & 0.959 \\
\hline$N$ & 1,610 & 1,610 & 1,610 & 1,610 \\
\hline
\end{tabular}

Notes: Dependent variable is real daily turnover by sector. All equations also contain day of week dummies, month dummies, a dummy to represent weekends when shops opened on Sunday as well as Saturday, and a constant. Numbers equation also contains six subperiod dummy variables to control for the variety of numbers game regimes during the sample period.

$*, * *$, and $* * *$ denote significant coefficients at $10 \%, 5 \%$, and $1 \%$ levels, respectively. 
each betting sector. By far, the largest sector by volume is horse race wagering. Here, the results on dummy variables that are not shown (for reasons of brevity) confirm that Saturday was easily the most popular day for betting and that the spring and mid-summer months were busier than the autumn and winter. Month dummies included two for June according to whether or not it was an even numbered year. In the June of an even numbered year, a month long international football tournament (the World Cup or European Championship) is held and there appears, from our results, to be strong displacement of horse betting by football betting on these occasions.

Among variables shown in Table 2, the number of shops operated by the company on each day served as a control; variation was due to branch openings and closures and acquisitions of shops owned by smaller bookmakers. Horse race betting turnover is found to be positively associated with shop openings, as the company would hope.

"Week number" was our trend variable and attracted a large and significant negative coefficient. Horse race betting declined in popularity over the data period. However, beyond our sample, there was a sharp increase in business reported by the industry from late 2001 onward, partly in response to the overall reduction in betting tax imposed in October 2001 (Paton, Siegel, and Vaughan Williams 2004). ${ }^{11}$

The quantity and quality of the horse racing on offer are naturally of extreme importance in determining turnover. Quantity was captured by a series of variables, all highly significant: the total number of runners (and its square) in British races that day, the number of British televised races, and the number of British, Irish, and foreign races broadcast by satellite television to bookmakers (but not to domestic households). Results imply that more races were associated with increased

11. There was a fundamental change in tax regime in October 2001, 4 mo after our sample period ends. Betting duty was previously a turnover tax of $6.75 \%$. This was replaced by a $15 \%$ tax on bookmaker takeout. Effectively, the tax burden on betting was halved, and Paton, Siegel, and Vaughan Williams (2004) relate the consequent improvement in value to bettors to the subsequent rapid increase in betting turnover. However, the data used by Paton, Siegel, and Vaughan Williams were for all betting and so do not yield estimates of change in individual betting sectors such as horse racing. horse race betting but the result from the coefficient estimate on runners squared suggests diminishing returns. The number of runners at which betting turnover is maximized corresponds with approximately the number engaged on the busiest day of the year. For televised races, the impact on betting volume of screening more events in a day is positive throughout the range of observations but the negative coefficient on the squared term indicates diminishing marginal effects.

Quality was also important to bettors. This was captured by the total purse money offered to owners of winning and placed horses in that day's British races, and this variable attracted a large and significant positive coefficient. Dummy variables were used to account for the increases in betting that occur during certain major events that generate strong interest. Thus, the Grand National Steeplechase, held at Liverpool in the Spring, is the biggest betting event of the year, and bookmaker shops were also very busy with horse betting during "big meetings" (festivals at Ascot, Goodwood, and Cheltenham).

We included as regressors both current day and lagged 1-d values for the proportions of favorites and second favorites that won in British horse races. All four coefficient estimates were positive and highly significant. British bookmakers typically hold unbalanced books such that they pay out more in winnings when races are won by short-odds runners. ${ }^{12} \mathrm{An}$ increase in the proportions of winning favorites and second favorites will raise payouts on the day (and on the next day for clients who leave the shop before the race and collect their winnings later). We interpret the positive coefficients as reflecting a significant propensity of horse bettors to reinvest these gains into further wagering.

A final group of controls recognized the influence of other events outside horse racing. Various special football events such as the FA Cup Final, played on a Saturday afternoon in May, and England playing Scotland in the 1996 European Championship impacted negatively on horse betting. This may not be due exclusively to substitution between football

12. To summarize the Royal Commission on Gambling (1978): "if one of the fancied horses wins, the bookmakers lose, but if one of the outsiders wins, they win." The situation appears not to have changed because bookmaker firms' annual reports tend to attribute periods of depressed profits to unusual runs of wins by favorites. 
and horse betting: high-profile football draws large television audiences and may therefore keep bettors at home. The number of British dog races was also a significant negative influence, but this will reflect direct substitution as television is not a factor in that sport. ${ }^{13}$

The inclusion of this comprehensive set of control variables allowed us to build a model that accounted for the bulk of the variation in horse race betting that occurred over $1,610 \mathrm{~d}$ for which volume was recorded: the value of $R^{2}$ was .96 . This is a rather higher value than that found for the other bookmaker sectors that we model. The superior goodness of fit for horse race betting is because much of the bettor interest is driven by the quality of the program, which is captured by prize money. No variable corresponding to "purse" exists in other sectors; either there is no obvious measure (as in soccer) or there is no quality dimension at all (the case of numbers).

Our main focus of attention is the substitution between lottery play and horse race betting. Coefficients on lottery variables that are significant and negative at $10 \%$ or better are shown in bold in Table 2. In the cases of both Wednesday and Saturday lotto, the significant impacts of high prize draws on horse betting occur $2 \mathrm{~d}$ before, that is, on Monday and Thursday, respectively. The adverse effect is especially strong on Monday. Monday offers the least attractive horse race program of the week. An average Monday yields only three-quarters of average daily horse race betting turnover. Indeed, shops typically experience a net cash outflow on Mondays, as collection of winnings from the busy Saturday program exceeds wagers on the usually distinctly unglamorous set of races run at the beginning of the week. Such betting activity as occurs will include reinvestment by those visiting the shop primarily to collect payouts from Saturday. Our interpretation of the results is that, given the weakness of the racing on offer, some stakes will be diverted to lotto tickets when the lotto prize is high. Similarly, later in the week, any impact on betting from lotto rollovers and Superdraws is indicated to occur on Thursday, when horse race betting turnover is also lower than the weekly average. Friday and especially Saturday are the biggest

13. Our models distinguish between dog races at meetings beginning in the morning and those later in the day. Morning races, held before horse meetings start, are subsidized by the betting industry to extend betting hours
TABLE 3

Short-Run Percentage Impacts of a Bonus Draw on Betting Turnover

\begin{tabular}{llll}
\hline Day of Turnover & Horse Racing & Soccer & Numbers \\
\hline Wednesday bonus & & & \\
$\quad$ Same day & & -13.34 & \\
$\quad \begin{array}{l}\text { Monday } \\
\text { Saturday bonus }\end{array}$ & -3.36 & & \\
$\quad$ & & -2.51 \\
Same day & & & \\
$\quad$ Thursday & -2.64 & & \\
\hline
\end{tabular}

Note: Impacts shown are for a bonus draw with amount added to the jackpot equal to the mean for bonus draws.

days of the week for horse betting and the highest quality races are usually scheduled then. Given this, horse bettors appear reluctant to forego wagers, whereas they appear less committed to the horses on Thursday.

The relative importance of special lotto draws for Monday horse race betting is shown in Table 3. This displays the short-run percentage impact on average betting turnover on a particular day if the value of BONUS is increased from 0 to its mean across those draws that were rollovers or Superdraws, on Wednesday or Saturday as appropriate. We see that the larger proportionate adverse effect on horse betting is from a Wednesday bonus to Monday betting, estimated at $-3.36 \%$. Translated into absolute (2001) pounds, this implies, at this particular bookmaker chain, a fall of $£ 103,530$ when there is a lotto special draw 2 d later (and where the amount added to the Lottery jackpot is the mean across all such rollovers or Superdraws). The impact of lottery on Thursday horse race turnover is slightly less.

The impacts on horse race betting are modest in size, but it is of interest that they occur ahead of the day of the special lotto draw. It is quite common to question the rationality of gamblers given that they repeatedly accept propositions with negative expected value. However, "rationality" has many levels of meaning, and Conlisk (1993) demonstrated that gambling, even by risk averse individuals, is consistent with expected utility maximization so long as they extract a limited amount of utility from the gambling process itself. ${ }^{14}$

14. The amount of utility has to be limited since otherwise the individual would act as if risk loving and be willing to gamble away the whole of personal wealth. 
The notion that gambling markets may be analyzed assuming participants' rationality in the conventional economic sense is supported when bettors respond to changes in relative prices in the same way as consumers of other goods and especially, as here, when they appear to engage in forward-looking behavior.

\section{B. Dog Race Betting}

Column 2 of Table 2 shows results for dog race betting turnover. The overall goodness of fit is less than for horse racing but still substantial with $R^{2} \mathrm{i}=.80$. The impacts of control variables on dog race turnover appear plausible. Saturday was again the peak day for betting and December was the busiest month, partly reflecting that dog racing is less prone than horse racing to the frost and waterlogged courses that plague the winter horse racing season. The weekly trend was again downward, although this was offset by the positive impact of opening extra shops. The number of dog races impacts positively upon betting with a larger impact in the afternoon relative to mornings. A higher rate of winning favorites encouraged dog race betting on the same day, a parallel result to horse race betting. Impacts from other sports are broadly adverse. For example, a greater number of horse races shown on television lowered betting, presumably because potential bettors stayed at home. Also, a greater number of horse races screened in betting shops reduced dog race betting.

We appear then to have been successful in capturing the principal determinants of the volume of dog betting. However, no impacts from lotto events were detected and for this group of bettors, lotto does not appear to be a substitute product.

\section{Soccer Betting and Numbers Games}

In season, soccer matches may be scheduled for any day of the week, but the majority is played on Saturday afternoons and the bulk of betting takes place on that day. Sometimes, there is a full midweek program or a round of an elimination tournament or there are matches rescheduled after bad weather, and there is therefore often a reasonable choice of games available for wagering on Wednesday evenings as well. Typically, and in contrast to most horse and dog races, betting is open for a few days prior to the event. But bettors are wise to place bets on the day of the game because British and
European soccer betting has the unusual institutional feature that odds are fixed for the duration of the betting period so that late news, on player injuries or team selection, for example, is not factored into the odds, giving the client an advantage over the bookmaker when he bets late. This reinforces the tendency for soccer turnover to be highest on Saturday, with Wednesday the next most popular day.

Controls to account for the quantity and quality of the soccer schedule are strongly significant with expected signs and relative magnitudes and this helps the model achieve high goodness of fit $\left(R^{2}=.89\right)$. There is a large negative impact from high-profile events in other sports such as the Grand National Steeplechase and Wimbledon tennis. The impacts are likely to follow from a combination of some bettors switching the subject of their bets and others staying in front of a television instead of going out to the bookmaker's.

Lotto rollovers and Superdraws do not appear to impinge on Saturday betting, but there is a very strong proportionate effect on Wednesday volume as the prize offered in that day's lottery draw is increased. There is some similarity with horse betting in this finding. Saturday offers the fullest opportunities for soccer betting, and bettors are unwilling to give up their regular activity on this day. But Wednesday soccer betting is more discretionary because its attractiveness and availability varies from week to week in any case. Prospectively high lotto jackpots are successful in drawing funds that would otherwise have been wagered on Wednesday night soccer. Wednesday soccer and Wednesday lotto are clear substitutes.

In common with other betting categories, the numbers sector attracts most interest on Saturdays. This is when leisure time is most available, when potential clients are most likely to be in the shop anyway (to bet on important horse and soccer programmes), and when the largest choice of games is offered. ${ }^{15}$

From Column 4 of Table 2, we see that some sporting events appear complementary to numbers betting, probably because they attract more customers to the betting shop or keep them there longer (e.g., number of dog races and the football World Cup). Other

15. Betting on which numbers will be drawn in foreign lotteries, such as those in Ireland and some American states, is popular. Many such lotteries hold their draws on Saturdays. 
sporting events displace numbers betting (the Grand National and Wimbledon tennis, e.g., both of which are more likely to be viewed at home). This suggests that numbers betting may not be a primary activity but an add-on to visits to the shop to bet on more traditional events. As such, we would view numbers betting as highly discretionary for regular bettors. This, and the similarity of product with lotto, lead us to expect a substitution effect. Such an effect was indeed detected, with a strongly significant negative coefficient, but only on Saturday and with a relatively low implied degree of cross elasticity.

\section{CONCLUSIONS}

Betting and lotteries are very different products. The former (except for numbers games) is an activity requiring skill where participants have to seek out value, whereas the latter is a game of pure chance. Betting, unburdened by the requirement to fund Good Causes and with keen competition between suppliers, offers a much higher mean return but without the skewness in returns, which seems fundamental to the appeal of lotto. Betting attracts only a minority of the population, whereas more than one half of adults play UK lotto. Betting is regarded as hard gambling because there is often opportunity to chase losses, but lotto is almost never regarded as a source of social problems. For all these reasons, it would not be surprising if clients of bookmakers and of the National Lottery were self-contained groups supporting products that were scarcely in competition with each other.

Examination of official household expenditure statistics reveals, however, that there is positive correlation between spending on betting and on lotto and that a large majority of bookmakers' customers also participates in the lotto game. Further, the empirical estimates that are the subject of this article show bettors responding to changes in the value offered by lotto tickets in three of four betting categories (dog bettors comprising the group impervious to lotto events). In soccer betting, there appears to be a substantial diversion of stakes in the direction of the lottery booth when there is a particularly attractive midweek lotto draw. In horse and numbers betting, statistically significant but quantitatively small substitution is observed. In horse betting, it is particularly interesting that the impact of large jackpots is felt $2 \mathrm{~d}$ ahead of the lotto draw. The greatest proportionate effect on horse betting volume is felt on those Mondays when there is an attractive midweek lottery draw scheduled for Wednesday. On Mondays, clients are likely to be in the bookmaker shop primarily to collect winnings, reinvestment of which would otherwise be into a usually uninspiring Monday racing program. The result suggests that a reduction in lotto takeout would draw money away from betting. However, it would only be fringe race meetings that would be threatened as no tendency is observed for diversion of expenditure on the days of the week (Friday and Saturday) when "big" racing is scheduled.

Since 2001, sales of lottery tickets in the United Kingdom, as in many other jurisdictions, have fallen significantly. This decline has coincided with a period when other forms of gaming have been made better value. This is particularly true for bookmaker betting, where a much more favorable tax regime was introduced in 2001. Moreover, other forms of gaming have been permitted for the first time, such as fixed odds betting terminals (offering games like electronic roulette) now available in betting shops. At the same time, lottery take-out rates have remained set as at inception in 1994.

Our results illustrate a certain willingness of players to reallocate their gambling budgets between the betting and the lottery as value for money changes from lottery draw to lottery draw. By implication, some of the loss in lottery sales since 2001 is likely to be attributable to the large change in the relative prices of the two products associated with reform of betting tax. Just what proportion of the loss is associated with cross-price effects is difficult to establish: many mature lotteries experience flagging sales, even with no major price changes for competing products, once players become bored with the games offered.

Although it is impractical to construct precise measures of cross-price elasticity for the present period, analysis of our bookmaker's data clearly indicates that the lottery is likely to be in a substitution relationship with gambling in general and betting in particular. Given the increasingly competitive gaming environment, it is unlikely to be optimal that the lottery cannot respond, under the current regulatory regime, to downward pressure on 
prices elsewhere by varying the takeout on its own product offering.

\section{APPENDIX. LIST OF CONTROL VARIABLES}

Shops: number of shops open.

Week: weekly time trend.

Month dummies: January to November with December excluded; June is split into June with no international soccer tournament and June with World Cup or European Championship.

Day of week dummies: Monday to Saturday with Wednesday excluded plus a dummy indicating that shops were open on Sunday (where Sunday turnover is included in Saturday figures).

Prize money: total prize money offered in UK horse racing that day deflated by Retail Price Index.

Total runners: total number of runners in UK horse races.

Grand National: dummy for the day of the Grand National Steeplechase (normally a Saturday).

Big meeting: dummy for a day of one of the major Festival horse race meetings at Ascot, Goodwood, or Cheltenham.

$T V$ races: number of UK horse races broadcast on terrestrial television that day.

Bookmaker non-TV races: number of UK horse races broadcast solely to bookmaker shops by satellite television.

Foreign $T V$ : number of foreign (including Irish) horse races relayed to bookmaker shops by satellite television.

1st favourite won: proportion of UK horse races won that day by the favorite.

2nd favourite won: proportion of UK races won that day by the second favorite.

Morning dog races: that day's number of UK dog races at meetings with a morning start.

Afternoon dog races: that day's number of UK dog races at meetings with an afternoon start.

Total dog races: sum of Morning dog races and Afternoon dog races.

Winning dog favourite: proportion of dog races won that day by the favorite.

Bank holiday soccer: dummy for a public holiday with a full English soccer programme.

Bank holiday Scottish soccer: dummy for day of a public holiday in Scotland only, with full Scottish soccer programme.

England in tournament match: dummy for a day during the World Cup or European Championship when the England soccer team is playing.

World Cup Final: dummy for day of the World Cup Final.

England v Scotland (Euro 1996): dummy for day when England played Scotland in the European Championship 1996 soccer tournament.

England v Scotland (World Cup qualifier): dummy for $2 \mathrm{~d}$ when England played Scotland in the World Cup qualifying competition.
Scotland in Euro 1996: dummy for days when Scotland played in the 1996 European Championship.

FA Cup Final: dummy for day of the FA Cup Final (normally a Saturday in May).

European club match: dummy for a day when a British club is playing in a European competition (not the Final, normally Tuesday, Wednesday, or Thursday).

Wimbledon men's final: dummy for final of Wimbledon tennis tournament (on a weekend in July).

Rugby League Cup Final: dummy for the day of the Rugby League Cup Final.

England club in European final: dummy for a day when an English club appeared in a European Cup final.

British open golf: dummy for the period of the British Open Golf Championship.

The following variables were initially included in a general specification but dropped as their coefficients were not significant at $10 \%$ in any turnover sector equation:

FA Cup round: dummy for a day when a round of the FA Cup (other than the final) is played.

Soccer games: total number of Premier League and Division One games in England that day.

Rugby Union: dummy for a day when England played in rugby union's international tournament.

\section{REFERENCES}

Conlisk, J. "The Utility of Gambling." Journal of Risk and Uncertainty, 6, 1993, 255-75.

Department for Culture, Media, and Sport. Gambling Review Report. London: The Stationery Office, 2001.

Farrell, L., E. Morgenroth, and I. Walker. "A Time-Series Analysis of U.K. Lottery Sales: Long and Short Run Price Elasticities." Oxford Bulletin of Economics and Statistics, 61, 1999, 513-26.

Forrest, D., R. Simmons, and N. Chesters. "Buying a Dream: Alternative Models of Demand for Lotto." Economic Inquiry, 40, 2002, 485-96.

Kaplan, H. "The Effects of State Lotteries on the PariMutuel Industry." Journal of Gambling Studies, 6, 1990, 331-44.

Mintel. Betting Shops-UK. London: Mintel International Group Limited, 2003.

Paton, D., D. Siegel, and L. Vaughan Williams. "A Time Series Analysis of the Demand for Gambling in the United Kingdom." National Tax Journal, 57(4), 2004, 847-61.

Purfield, C., and P. Waldron. "Gambling on Lotto Numbers: Testing for Substitutability or Complementarity Using Semi-Weekly Turnover Data." Oxford Bulletin of Economics and Statistics, 61, 1999, 527-44.

Royal Commission on Gambling. Report (Cmnd 7200). London: HMSO, 1978.

Simmons, S., and R. Sharp. "State Lotteries' Effects on Thoroughbred Horse Racing." Journal of Policy Analysis and Management, 6, 1987, 446-8.

Swiss Institute of Comparative Law. Study of Gambling Services in the Internal Market of the European 
Union. Lausanne, Switzerland: Swiss Institute of Comparative Law, 2006.

Thalheimer, R. "The Impact of Interstate Intertrack Wagering, Casinos and a State Lottery on the Demand for Pari-Mutuel Horse Racing, " in Gambling and Commercial Gaming, edited by W. Eadington and J. Cornelius. Reno, NV: The Institute for the
Study of Gambling and Commercial Gaming, 1992, 285-94.

Thalheimer, R., and M. Ali. "The Demand for PariMutuel Horserace Wagering and Attendance with Special Reference to Racing Quality, and Competition from State Lottery and Professional Sports.' Management Science, 41, 1995, 129-43. 